\title{
Active Learning and New Technologies in Business and Economics Higher Education: The Je Suis Econplus Experience ${ }^{+}$
}

\author{
Luis R. Murillo-Zamorano ${ }^{1, *}$, José Ángel López-Sánchez ${ }^{2}$ and Ana Luisa Godoy-Caballero ${ }^{3}$ \\ 1 Department of Economics, University of Extremadura, Avda. de Elvas s/n, 06006 Badajoz, Spain \\ 2 Department of Business, University of Extremadura, Avda. de Elvas s/n, 06006 Badajoz, Spain; \\ jangel@unex.es \\ 3 Department of Economics, University of Extremadura, Avda. de la Universidad s/n, 10071 Cáceres, Spain; \\ anagodoycaballero@unex.es \\ * Correspondence: lmurillo@unex.es; Tel.: +34-924289300 (ext. 89197) \\ + Presented at the 2nd Innovative and Creative Education and Teaching International Conference \\ (ICETIC2018), Badajoz, Spain, 20-22 June 2018.
}

Published: 28 October 2018

\begin{abstract}
The objective of this research is to present an innovative and successful active learning experience aimed at enabling the development of students' knowledge, skills and engagement in a Higher Education setting - the Je Suis Econplus experience.
\end{abstract}

Keywords: flipped learning; gamification; knowledge; skills; engagement; new technologies; Je Suis Econplus

\section{Introduction}

The delivery of lectures in Higher Education is changing from a teacher-centered perspective into a student-centred panorama, among which we can highlight the Flipped Learning approach [1], mainly characterized by a change in the place where the activities take place so that those ones normally developed outside the classroom now occur in it, and vice versa [2]. During the time spent in class, the teaching-learning process focuses on those parts of the materials where students have manifested to present more troubles [3-7]. All this supported with the presence of a timely feedback $[8,9]$, and the use of New Technologies, recognized as having a crucial role in the process of inverting the classroom [6,9-11].

Despite the multiple advantages that inverting the classrooms exhibits, students need to make higher efforts as a result of the increase in their workload [12]. Furthermore, active learning methodologies require a high level of interaction between students, leading to having to continuously motivate them, something that cannot be achieved easily. The application of the elements of a game into the teaching-learning process, something known as Gamification, has been used to solve such inconvenient. The incorporation of Gamification makes the learning process more enjoyable $[13,14]$ as it helps solving problems and keeps students motivated.

Considering all the aforementioned, the objective of this research is to present an innovative and successful active learning experience aimed at enabling the development of students' knowledge, skills and engagement in a Higher Education setting. In doing so, a successful project in education innovation is being developed at the University of Extremadura (UEx), through an experience called Je Suis Econplus. The main element of such experience is the students, who reveal their preferences for a change in Higher Education teaching-learning processes, and the positive outcomes that such a change provides to students. 
In order to achieve that objective, we have structured the paper as it follows. In the next section, we present the main characteristics of the Je Suis Econplus experience. Then, we show its results by looking at how it benefits students, and by analyzing how the experience has been received outside the university. Finally, we conclude the paper.

\section{Material and Methods}

We now move to the presentation of the characteristics of the Je Suis Econplus experience. It was born in the Faculty of Business and Economics at the University of Extremadura (Spain) during the academic year 2016-2017. The experience is based on the joint use of 6 main components: (1) Flipped Learning, (2) Gamification, (3) Social Networking, (4) Cloud, (5) Engagement, and (6) Active Learning.

As previously mentioned, the main protagonists of the active learning experience are the students. Therefore and in order to allow them to have such an active participation in the teachinglearning process, we started by flipping the lectures, designing an inverted-classroom model that took into account all the main elements that the literature has considered as essential when implementing this type of methodology: out-of-class activities, feedback, in-class activities, and the use of the new technologies. The out-of-class activities are developed by students during their study time before the actual lecture takes place. During this time, their learning is complemented by a series of YouTube video tutorials made available by the teacher in the online platform Blendspace. After watching the videos they have to summarize them and upload their summary to the virtual learning environment (VLE), completing, at the same time, a questionnaire related to their work and the aspects where more attention needs to be paid during the class time. These are the elements where the instructor focuses at the beginning of the lectures, commenting the feedback received and redesigning all the learning-teaching activity based on students' comments, therefore, following a justin-time teaching approach [1]. The rest of the in-class time is based on student-centered learning activities [7], which development is supported by a virtual learning community located in Google+, where students and the lecturer could share additional resources, ask and solve doubts, publish relevant news, and co-evaluate the resolution of problems and practical exercises from other colleagues.

In order to overcome the Flipped Learning limitations and to enhance the teaching-learning process, within the Je Suis Econplus initiative we also include Gamification activities, materialized in the ECONPLUS CHAMPIONS LEAGUE. It consists of a competition which allows to increasing a series of students' competences as well as to continuously motivate them, and to increasing the level of interaction between them. To the joy and happiness of the students for learning is added the presentation of a successful YouTube channel: Je Suis Econplus Official (https://www.youtube.com/c/JESUISECONPLUS_OFFICIAL). The motto of this YouTube channel is summarized as follows: "ECONOMICS STUDENTS-TO-STUDENTS: Digital Transformation and Active Learning of Economics in Higher Education through Flipped Learning, Gamification and New Technologies".

\section{Results and Discussion}

In this section, we show the results obtained from our experience. First of all, we present its impact on the acquisition of knowledge, skills and engagement. A total of 112 students, most of them having attended more than $80 \%$ of the sessions expressed their opinions about the impact of the Je Suis Econplus experience. Figure 1 shows students' views about how the flipped learning methodology helps them improved their knowledge, skills and engagement. In relation to knowledge, we are interested in whether the new approach helps students understand the contents and better prepare the final exams, obtaining, for both variables, agreement rates over $60 \%$. 


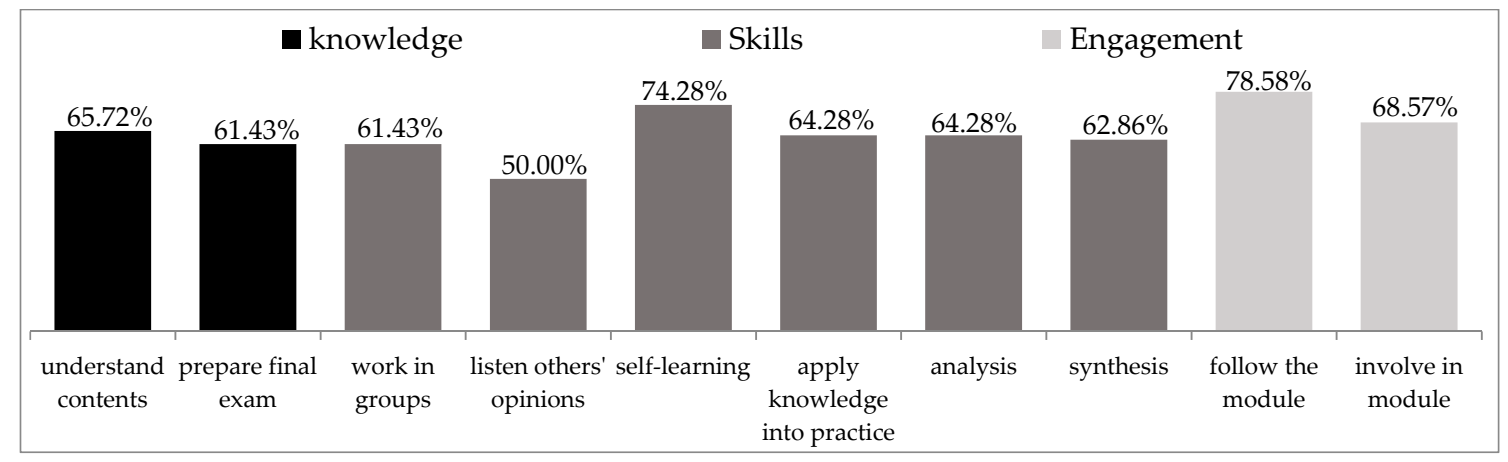

Figure 1. Impact of flipped learning on knowledge, skills and engagement.

When looking at skills, we study whether the new teaching methodology increases the ability to (1) work in teams, (2) listen to classmates' opinions, (3) learn autonomously, (4) apply knowledge into practice, (5) analyze, and (6) synthetize the material. Among them, flipping the classroom mainly improved the self-learning ability, the analytical skills, and the teamwork ability, with agreement rates over $60 \%$. Concerning engagement, we focus on whether students follow the module more easily and whether their involvement with it increases, finding that the wide majority of students agreed on the implementation of this teaching-learning methodology as a way to improve their levels of engagement.

The incorporation of gamification techniques, reproduced in the ECONPLUS CHAMPIONS LEAGUE, significantly improves students' abilities. Figure 2 shows students' levels of agreement on whether the combination of flipped learning and gamification enhances the studied abilities, obtaining higher agreement rates, for all the skills analyzed, in comparison with the approach which only flips the classroom.

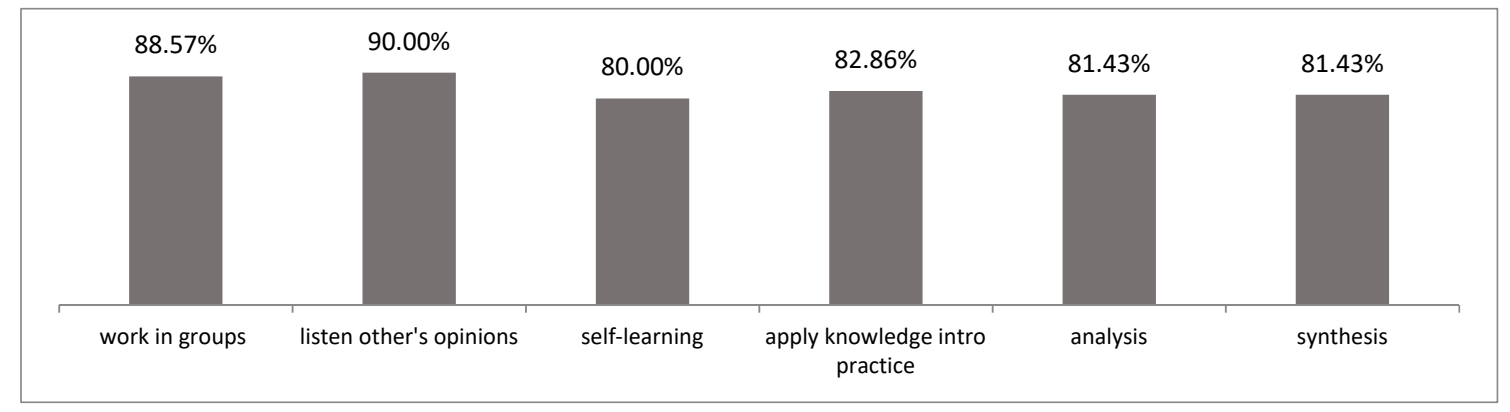

Figure 2. Impact of flipped learning and gamification on skills.

Additionally, students' levels of satisfaction with this experience of digital transformation of the learning of Economics in Higher Education have been collected and presented in a video that won the second prize in the tenth edition of the "CREA Universidad" competition. Organized by the Rectorate of the University of Extremadura, its objective was to establish new channels for the participation of members of the university community in the different fields of cultural creation and communication, promoting the dissemination of innovative and quality proposals that arise within it. The video with students' opinions is entitled "Je Suis Econplus-The Movie" and is available at https://youtu.be/dfSO2_Ksedk. Finally, since its presentation to the digital world on 7 February 2017, the YouTube channel-Je Suis Econplus Official-has reaped 32,083 views and 749 subscribers (as of 1 May 2018).

\section{Conclusions}

Our paper has presented an innovative and successful active learning experience, Je Suis Econplus, being students the main elements of it. The active learning methodology combines flipped classroom and gamification with the aim of enabling the development of students' knowledge, skills and engagement in Higher Education. In the advance of such experience students have revealed their 
preferences for such a change in Higher Education teaching-learning processes, as their knowledge, skills and level of engagement have improved. Such and increase has also been present in students' levels of satisfaction with the experience. All this has led to the following conclusion: The future cannot wait, the Je Suis Econplus experience is here.

Author Contributions: All authors contributed equally.

Acknowledgments: We would like to acknowledge the funding of the European Regional Development Fund [N. Exp. GR15044], the Government of Extremadura (Junta de Extremadura) [N. Exp. GR15044]; the Servicio de Orientación y Formación Docente (SOFD) of the University of Extremadura [YOUTUBE_PROES].

Conflicts of Interest: The authors declare no conflict of interest.

\section{References}

1. Camp, M.E.; Middelndorf, J.; Sullivan, C.S. Using Just-in-Time Teaching to Motivate Student Learning. In Just-in-Time Teaching: Across the Discipline, Across the Academy; Simkins, S., Maier, M., Eds.; Stylus Publishing; Sterling, VA, USA, 2010.

2. Lage, M.J.; Platt, G.J.; Treglia, M. Inverting the classroom: A gateway to creating an inclusive learning environment. J. Econ. Educ. 2000, 31, 30-43.

3. Bates, S.; Galloway, R. The Inverted Classroom in a Large Enrolment Introductory Physics Course: A Case Study, 2012. Available online: http://www2.ph.ed.ac.uk/ rgallowa/Bates_Galloway.pdf (accessed on 1st May 2018).

4. Roach, T. Student Perceptions towards Flipped Learning: New Methods to Increase Interaction and Active Learning in Economics. Int. Rev. Econ. Educ. 2014, 17, 74-84.

5. Love, B.; Hodge, A.; Grandgenett, N.; Swift, A.W. Student Learning and Perceptions in a Flipped Linear Algebra Course. Int. J. Math. Educ. Technol. 2014, 45, 317-324.

6. Hung, H.T. Flipping the Classroom for English Language Learners to Foster Active Learning. Comput. Assist. Lang. Learn. 2015, 28, 81-96.

7. O'Flaherty, J.; Phillips, C. The Use of Flipped Classrooms in Higher Education: A Scoping Review. Internet High Educ. 2015, 25, 85-95.

8. Roehl, A.; Reddy, S.L.; Shannon, G.J. The Flipped Classroom: An Opportunity to Engage Millennial Students through Active Learning. J. Fam. Consum. Sci. 2013, 105, 44.

9. Elmaadaway, M.A.N. The Effects of a Flipped Classroom Approach on Class Engagement and Skill Performance in a Blackboard Course. Br. J. Educ. Technol. 2017, doi:10.1111/bjet.12553.

10. Strayer, J.F. How Learning in an Inverted Classroom Influences Cooperation, Innovation and Task Orientation. Learn. Environ. Res. 2012, 15, 171-193.

11. Butt, D. Student Views on the Use of a Flipped Classroom Approach: Evidence from Australia. Buss. Educ. Accred. 2014, 6, 33-43.

12. He, W.; Holton, A.; Farkas, G.; Warschauer, M. The effects of flipped instruction on out-of-class study time, exam performance, and student perceptions. Learn. Instr. 2016, 45, 61-71.

13. Azmi, M.A.; Singh, D. Schoolcube: Gamification for learning management system through microsoft sharepoint. Int. J. Comput. Games Technol. 2015, 2015, 589180.

14. Yildrim, I. The effects of gamification-based teaching practices on student achievement and students' attitudes toward lessons. Internet High Educ. 2017, 33, 86-92.

(C) 2018 by the authors. Licensee MDPI, Basel, Switzerland. This article is an open access article distributed under the terms and conditions of the Creative Commons Attribution (CC BY) license (http://creativecommons.org/licenses/by/4.0/). 